\title{
Calogênese do híbrido Theobroma grandiflorum x $T$. obovatum (Sterculiaceae) ${ }^{1}$.
}

\author{
Giorgini Augusto VENTURIERI ${ }^{1}$ Giorgio Cristino VENTURIERI ${ }^{2}$
}

\begin{abstract}
RESUMO
O declínio da cacauicultura na amazônia tem sido causado pela doença vassoura-de-bruxa (Crinipellis perniciosa). Um híbrido interespecífico do mesmo gênero (Theobroma grandiflorum $\mathrm{x}$ T. obovatum) tem demonstrando resistência a esta doença. Avaliou-se a calogênese deste híbrido com a finalidade de sua propagação massiva. Os explantes usados (tegumento, cotilédone e embrião) foram postos para desenvolver em condições estéreis em meio de cultura LPm mais água de coco $(50 \mathrm{ml} / \mathrm{l})$, glucose $(20 \mathrm{~g} / \mathrm{l}), 2,4$ - D $(2 \mathrm{mg} / \mathrm{l})$, Thidiazuron - TDZ nas concentrações de 0,5 e $10 \mu \mathrm{g} /$, carvão ativado $(2 \mathrm{~g} /$ ) em gelrite $(2 \mathrm{~g} / 1)$ a um pH de 5,8. Cada concentração de TDZ x tipo de tecido foi considerado um tratamento. As culturas foram mantidas no escuro, à temperatura de $22 \pm 2{ }^{\circ} \mathrm{C}$. Os tecidos não mostraram diferenças significativas quanto a proporção do explante recoberto por calos $(p=0,14)$ embora notou-se que nos cotilédones tenha sido maior. A dosagem de TDZ nitidamente não influenciou no recobrimento de calos $(p=0,94)$. Quanto a freqüência, os tecidos mostraram diferentes capacidades de desenvolver calos $(p=0,02)$ sem mostrar-se influenciados pela dosagem de TDZ ( $p$ $=0,66$ ). Os explantes de cotilédones foram os que formaram calos em maior freqüência. Houve uma leve tendência de que quanto menor a dosagem de TDZ maior a freqüência de calos obtidos. Não foi constatada interação entre tipo de calo/frasco $\mathrm{x}$ dosagem de TDZ $(p=0,32)$.
\end{abstract}

\section{PALAVRAS-CHAVE}

cupuaçu híbrido; cultura-de-tecido, Vassoura-de-bruxa, micropropagação

\section{Calogenesis of Theobroma grandiflorum $x$. T. obovatum bibrid (Sterculiaceae).}

\begin{abstract}
Decline of cocoa plantations in Amazonia has been attributed to Witches-broom-disease (Crinipellis perniciosa). An interspecific bybrid (Theobroma grandiflorum $x$ T. obovatum) has demonstrated resistance to this disease. Calogenesis of this hybrid was evaluated, in preparation for its mass propagation. The explants used (tegument, cotyledons and embryos) were developed in sterile conditions in LPm media plus coconut milk $(50 \mathrm{ml} / \mathrm{l})$, glucose $(20 \mathrm{~g} / \mathrm{l}), 2,4-\mathrm{D}(2 \mathrm{mg} /$ l), Thidiazuron - TDZ at concentrations of 0,5 e $10 \mu \mathrm{g} / \mathrm{l}$, and activated charcoal $(2 \mathrm{~g} / \mathrm{l})$ in gelrite $(2 \mathrm{~g} / \mathrm{l})$ at pH 5.8. Each concentration of TDZ $x$ kind of explant was considered a treatment and were kept in the dark at a temperature of $22 \pm$ $2{ }^{\circ} \mathrm{C}$. Explants did not show significant differences in the proportion of callus recovery $(\mathrm{p}=0,14)$ although cotyledons did have the highest value. TDZ level did not influence callus recovery $(\mathrm{p}=0,94)$. Different explants resulted in different frequencies of callus development $(\mathrm{p}=0,023)$ but were not been influenced by the doses of TDZ $(\mathrm{p}=0,66)$. Cotyledon explants displayed the highest values for frequency of callus development. There was also a slight trend that lower levels of TDZ resulted in higher frequencies of callus development. There was no interaction between kind of callus/ flasks $x$ doses of TDZ $(\mathrm{p}=0,32)$.
\end{abstract}

\section{KEY WORDS}

cupuassu bybrid, tissue-culture, witches-broom-disease, micropropagation

\footnotetext{
${ }^{1}$ Estudos financiados pelo Conselho Nacional de Pesquisa e Desenvolvimento Tecnológico (CNPq)/ Programa do Trópico Úmido (PTU) (proc. ${ }^{\circ}$ 469915/00-5).

${ }^{2}$ Professor Doutor da Universidade Federal de Santa Catarina, Centro de Ciências Biológicas, 88.040-900, Florianópolis - SC, Brasil, giorgini@ccb.ufsc.br

${ }^{3}$ Eng. Agrônomo., D.Sc. da Embrapa Amazônia Oriental, Caixa. Postal 48, CEP: 66.095-100, Belém, PA, giorgio@cpatu.embrapa.br.
} 


\section{ACTA \\ AMAZONICA}

CALOGÊNESE DO HÍBRIDO Theobroma

grandiflorum X T. obovatum (STERCULIACEAE)

\section{INTRODUÇÃO}

O cacau (Theobroma cacao) possui importância econômica mundial, pois sua amêndoa é matéria para fabricação de chocolate. Tem também uma grande importância social, pois é uma cultura que utiliza muita mãode-obra. O declínio da produção cacaueira brasileira tem sido causado pela doença Vassoura-de-bruxa (Crinipellis perniciosa) e está contribuindo para o êxodo rural no Sul da Bahia e na Amazônia. Embora estejam sendo feitos esforços para a obtenção de variedades de cacau resistentes a esta doença, outras espécies e híbridos interespecíficos do mesmo gênero poderiam ser testados e explorados como análogos ao cacau e que exibissem alguma resistência a doença.

Um híbrido, o de Theobroma grandiflorum $\times$ T. obovatum, feito por Addison \& Tavares $(1951,1952)$, vem demonstrando resistência parcial à doença Vassoura-de-bruxa. No entanto, restam apenas 5 das matrizes originais, na hoje nomeada coleção “Addison O'Neill”, pertencente a EMBRAPA - Amazônia Oriental em Belém - PA, Brasil, com grande risco de virem a ser perdidas. A propagação deste híbrido, por métodos massivos como a propagação in vitro, poderia propiciar a formação de estandes para futuros testes agronômicos e diminuir o risco de perda de tal material genético.

A formação de calos em um explante, denominada calogênese, é uma etapa básica para o desenvolvimento de sistemas de propagação massiva de plantas por organogênese ou embriogênese somática. É útil também quando se deseja produzir células para manipulações genéticas, como hibridações somáticas, poliploidizações e transformações.

Das 8 espécies amazônicas de Theobroma, a propagação in vitro de apenas duas delas tem sido avaliada. Para T. cacao, tem-se feito consideráveis esforços para estabelecer um método de propagação baseado em cultura de tecidos. Porém, a sua recalcitrância in vitro e a sua grande relação com o genótipo dificultam a obtenção de um eficiente sistema de micropropagação via organogênese ou desenvolvimento de gemas axilares (Orchard et al., 1979; Passey \& Jones, 1983; Blake \& Maxwell, 1984; Janick \& Whipkey, 1985; Dufour \& Dublin, 1985; Flynn et al., 1990; Figueira et al., 1991; Figueira \& Janick, 1994; Tan \& Furtek, 2003).

Um eficiente sistema de propagação foi desenvolvido por Li et al. (1998) com procedimentos para estimular a embriogênese somática e a regeneração de plantas a partir de tecidos florais (estaminódios), pela utilização de 3 etapas no cultivo (indução de calos, desenvolvimento de embriões e regeneração de plantas), em combinação com o uso da citocinina sintética TDZ (Thidiazuron) e da auxina sintética 2,4-D. Os resultados de Li et al. (1998) foram promissores, com 100\% dos estaminódios cultivados do genótipo Sca6-1 produzindo, em média, 45 embrióes somáticos por estaminódio. Estaminódios de vários outros genótipos foram testados (num total de 19 genótipos) e todos foram responsivos às condições de cultura, em taxas que variaram de 1 a 100 \% de eficiência, cada qual produzindo em média de 1 a 46 embrióes. Mais de 270 plantas, derivadas de embriões somáticos de seis desses genótipos, foram estabelecidas com sucesso em casa de vegetação. Esses resultados demonstraram uma maior aproximação da utilização no futuro de embriões somáticos obtidos em laboratório na propagação clonal de cacaueiros.

A outra espécie de Theobroma estudada foi o cupuaçu (T. grandilforum), que vem tomando importância para a indústria de sucos e como um possível sucedâneo para o cacau (Venturieri, 1993). Embriões imaturos desta espécie foram retirados de sementes e cultivados em meio MS suplementado com 2,4-D (1 mg/l) e água de coco (10 ml/ $)$, tendo sido obtido calos (Velho et al. 1988). Segmentos de eixo embrionário e de cotilédones foram cultivados em meio MS 1/2 + 2,4-D (1, 2, 4 e 8 mg/), sais do MS 1/1 (SIGMA) acrescido de ANA (3 mg/), sais do N6 (SIGMA) 4g/ + 2,4-D $(0,2,4 \mathrm{mg} / \mathrm{l})$ e ANA $(0,3,5 \mathrm{mg} / \mathrm{l})$, sais do N6 (SIGMA) acrescido somente de ANA (3 mg/). Calos brancos e brilhantes foram observados nos explantes testado no meio MS + 2,4D (1 e 2 mg/l). A combinação de ANA (3 mg/) e 2,4-D (2 mg/ 1) promoveram a formação de calos brancos e raízes mas não foram obtidas plântulas (Ferreira et al. 2001).

O objetivo do presente trabalho foi avaliar a calogênese de 3 diferentes tecidos obtidos da semente do híbrido $T$. grandiflorum $\mathrm{x}$ T. obovatum como o primeiro estágio para a obtenção de plântulas in vitro.

\section{MATERIAL E MÉTODOS}

Frutos completamente desenvolvidos, porém não completamente maduros e ainda portando o pedúnculo e um pedaço de ramo, provenientes da matriz GO-1 da coleção "Addison O'Neil" pertencente a EMBRAPA - Amazonia Oriental em Belém - PA, foram coletados em 16/10/2001. Os frutos foram envolvidos em papel jornal, mantidos em sacos plásticos (para manter a unidade e evitar disseminação de doenças) e transportados para Florianópolis - SC. No dia seguinte, os sacos plásticos foram abertos e mantidos à temperatura ambiente dentro de laboratório por 4 dias quando foram então usados.

Para a obtenção dos explantes, o fruto foi inicialmente esterilizado por imersão em Etanol 95\% (1 min.) seguido de imersão em solução de hipoclorito de sódio 40:60 v/v do produto comercial com $2,5 \%$ de cloro ativo: água, mais 3 gotas de detergente de uso doméstico (20 min.). As sementes foram extraídas do fruto e despolpadas dentro de uma capela de fluxo laminar e re-imersas em uma nova solução de hipoclorito na mesma concentração e no tempo já citados. Foram então enxaguadas 3 vezes em água deionizada estéril por 1 minuto em cada vez. Os explantes (tegumento, cotilédone e embrião) retirados das sementes, foram postos para desenvolver em condições estéreis em meio de cultura LPm (macro, micronutrientes, vitaminas e aminoácidos do meio) (Von Arnold \& Erikson, 1981) acrescido de água de coco (50 ml/ $)$, glucose (20 g/), 2-4D (2 mg/), mais Thidiazuron - TDZ nas concentrações de 0,5 e $10 \mu \mathrm{g} / \mathrm{l}$ em gelrite $(2 \mathrm{~g} / \mathrm{l})$ mais carvão ativado (2 g/l) e pH ajustado a 5,8. Cada concentração de TDZ $\mathbf{x}$ tipo de tecido foi considerado um tratamento. Para cada 


\section{ACTA AMAZONICA}

CALOGÊNESE DO HÍBRIDO Theobroma

grandiflorum X T. obovatum (STERCULIACEAE) tratamento, foram utilizados 2 frascos, com capacidade para $500 \mathrm{ml}$, cada um contendo $40 \mathrm{ml}$ de meio. Em cada frasco foram colocados 5 explantes (considerados como repetições). As culturas foram mantidas no escuro, à temperatura de $22 \pm$ $2{ }^{\circ} \mathrm{C}$. No dia 22/11/2001, 33 dias após a colocação nos meios de cultura, a emissão de calos foi avaliada subjetivamente pela sua presença/ausência e extensão. Para esta última, foram atribuídas notas que variaram de 0 a 100 de acordo com a proporção de calo sobre a área exposta do explante (acima do meio de cultura), p. ex., $0=$ sem emissão de calo, $50=$ emissão moderada de calos correspondendo a aproximadamente 1/2 da região exposta, 100 = a emissão em $100 \%$ da área exposta. A qualidade do calo também foi avaliado subjetivamente atribuindo-se nota de 1 a 3 sendo: 1 calos amarelados, translúcidos formando uma superfície lisa, $2=$ calos amarelados, levemente opacos e friáveis, 3 = calos brancacentos, opacos, brilhantes e friáveis.

Para as análises estatísticas, os dados em proporção foram transformados para o arco seno da raiz de $p$, onde $p=$ a proporção (Sokal \& Rohlf, 1981), exceção feita para a análise de interação, onde foi usado o número absoluto de calos responsivos. Os dados foram inicialmente submetidos a análise de variância onde foi comparado o tipo de tecido $\mathrm{x}$ dosagem de TDZ (ANOVA dois critérios). Em uma segunda etapa, o tecido com maior resposta foi avaliado para tipo de calo observado $\mathrm{x}$ dosagem de TDZ e interação (ANOVA fatorial). A comparação de médias foi feita pelo teste de $t$ de Student usando o pacote estatístico Bioestat (Ayres et al., 1998).

Os calos gerados pelo melhor tratamento foram transferidos para um outro meio para a proliferação dos calos (MPC) com a mesma constituição anterior, exceto os hormônios, que foram a Kinetina - KIN nas concentrações de 1, 2 e 3 mg/ combinado com Ácido Naftaleno Acético - ANA 0,01 e 0,1 mg/.

\section{RESULTADOS E DISCUSSÃO}

A formação de calos iniciou-se ao longo da segunda semana de cultivo, a partir de pontos que se expandiam, e recobriam a superfície do explante (Figura 1).

Considerando a proporção de recobrimento entre os diferentes tecidos testados, embora os cotilédones tenham mostrado média mais elevada, as diferenças não foram significativas estatisticamente $(p=0,14)$. Quanto a dosagem de TDZ esta nitidamente não influenciou na cobertura de calos $(p=0,94)$ (Tabela 1).

Quanto a freqüência de explantes responsivos, os tecidos mostraram diferentes capacidades de desenvolver calos $(p=0,02)$ mas não se mostraram influenciados pela dosagem de TDZ $(p=0,66)$. Os explantes de cotilédones foram os que formaram calos em maior freqüência (Figura 2).

Em termos de freqüência de calos,

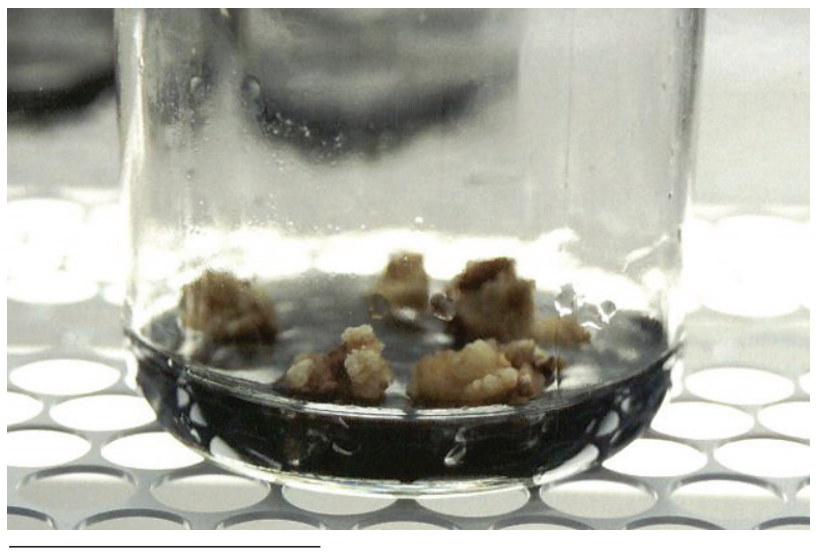

Figura 1 - Calos formados em cotilédones do híbrido de Theobroma grandiflorum x T. obovatum. Os calos marrons escuros são do "tipo 1", os marrons claros são do "tipo 2", e branco do "tipo 3".

independente do tecido e do tipo de calo, a dosagem de TDZ $5 \mu \mathrm{g} / \mathrm{l}$ foi o que provocou a melhor resposta para esse experimento (Tabela 2), mas este dado é incompleto pois o tipo de calo é fortemente associado a sua capacidade embriogênica. Analisando apenas o tecido cotilédone em termos da proporção da cobertura de calo por dosagem de TDZ, notou-se que não houveram diferenças estatisticamente significativas tanto para tipo de calo $(p=0,05)$ como para dosagem de TDZ $(p=0,58)$ (Tabela 2$)$. No entanto, os valores de $p$ para o fator tipo de calo foi próximo do limite significativo de $5 \%$, o que pode ser interpretado como um indicativo de que a presença de TDZ tenha influenciado mais na formação de calos do tipo 2, o que poderia ser melhor evidenciado em uma amostragem maior. Quanto a freqüência de calos responsivos, houve diferença significativa entre tipos de calos $(p=0,01)$ sendo o do tipo 2 o de maior freqüência e estatisticamente diferente dos demais. As freqüências de calos do tipo 1 e 3 foram equivalentes estatisticamente (Figura 3). Quanto a dosagem de TDZ, esta não influenciou significativamente $(p=0,11)$ embora haja indicadores de que quanto menor a dosagem de TDZ maior a freqüência de calos obtidos (Figura 3).

Não foi constatada interação entre tipo de calo/frasco $\mathbf{x}$ dosagem de TDZ $(p=0,32)$. Especificamente para os calos do

Tabela 1 - Valores médios da proporção (\%) da cobertura de calo em Theobroma grandiflorum $\mathrm{x}$ T. obovatum por dosagem de TDZ $\mathrm{x}$ tipo de tecido usado no explante. As diferenças não foram significativas estatisticamente para o tipo de tecido $(p=0,14)$, dosagem de TDZ $(p=0,94)$ e interação $(p=0,32)$.

\begin{tabular}{lcccc}
\hline \hline \multirow{2}{*}{ Tratamento } & \multicolumn{3}{c}{ Tecido } & Média/dosagem \\
\cline { 2 - 4 } & Embrião(\%) & Tegumento(\%) & Cotilédone(\%) & de TDZ(\%) \\
\hline TDZ 0 & 2,0 & 2,0 & 2,0 & 2,0 \\
TDZ 5 & 0,4 & 0,7 & 9,1 & 3,4 \\
TDZ 10 & 1,1 & 0,0 & 7,1 & 2,7 \\
Média/tecido & 1,2 & 0,9 & 6,1 & \\
\hline \hline
\end{tabular}


tipo 3, que são os considerados o de maior interesse por serem os de maior chance de tornarem-se embriogênicos, não foi constatada qualquer relação com a aplicação de TDZ (Figura 3).

O experimento indica que o TDZ não produziu melhoras na indução de calos desejáveis para virem a ser aproveitados para a organogênese ou embriogênese somática do híbrido de T. grandiflorum $\times$ T. obovatum diferentemente do que foi observado para o cacau por Li et al. (1998).

Os experimentos de Velho et al. (1988) e Ferreira et al. (2001) mostraram que o cupuaçu não tem apresentado

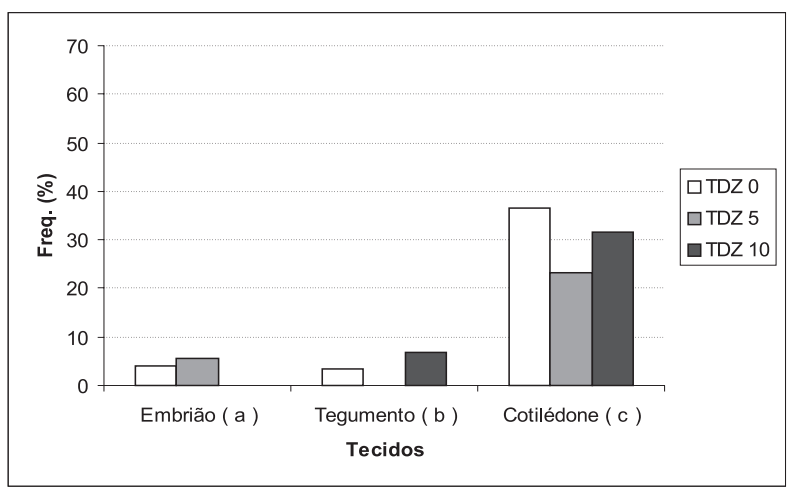

Figura 2 - Freqüência de calos em Theobroma grandiflorum $\mathbf{x}$ T. obovatum formados por tipo de tecido. As médias diferiram entre si ao nível de 5\%.

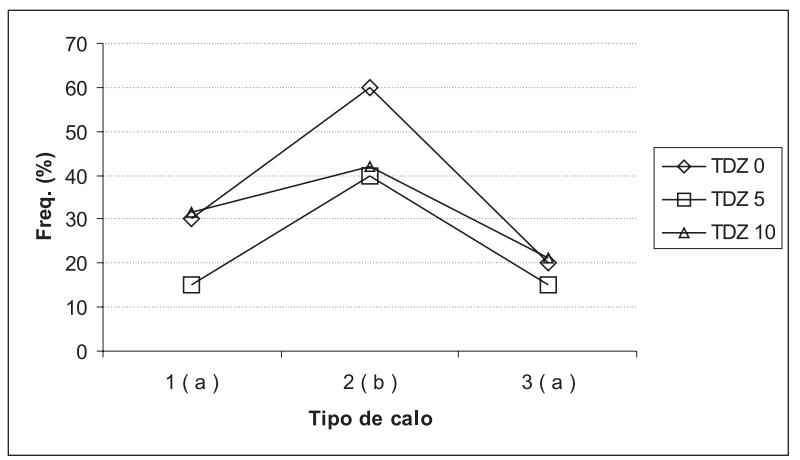

Figura 3 - Freqüência de calos em Theobroma grandiflorum x T. obovatum formados por frasco em explantes de cotilédones. Médias seguidas de mesma letra não diferem entre si ao nível de 5\%.

Tabela 2 - Valores médios da proporção (\%) da cobertura de calo em Theobroma grandiflorum $\mathrm{x}$ T. obovatum por dosagem de TDZ x tipo de calo obtido em cotilédones. Não houveram diferenças estatisticamente significativas para tipo de calo $(p=0,05) \mathrm{e}$ dosagem de TDZ $(p=0,58)$.

\begin{tabular}{lcccc}
\hline \hline Tratamento & \multicolumn{3}{c}{ Tipo de calo } & Média/dosagem \\
\cline { 2 - 4 } & $\mathbf{1 ( \% )}$ & $\mathbf{2 ( \% )}$ & $\mathbf{3 ( \% )}$ & de TDZ(\%) \\
\hline TDZ 0 & 8,3 & 36,5 & 2,1 & 2,0 \\
TDZ 5 & 4,1 & 33,3 & 2,0 & 15,6 \\
TDZ 10 & 22,1 & 20,9 & 7,7 & 13,1 \\
Média/tipo de calo & 11,5 & 30,2 & 3,9 & \\
\hline \hline
\end{tabular}

dificuldades para gerar calos usando-se o meio MS com a adição de baixas concentrações de 2,4-D, sendo a eficiência na emissão de calos aumentada pela adição de ANA. Como o cupuaçu é uma das espécies progenitoras do híbrido estudado, pode ser que ANA venha a provocar um maior crescimento de calos no híbrido T. grandiflorum $x T$. obovatum. No entanto, a avaliação do efeito de ANA e KIN foi prejudicado pelo elevado índice de contaminação. Nos dois frascos que não contaminaram, um contendo ANA 0,01 $\mathrm{mg} / \mathrm{l}$ e KIN $1 \mathrm{mg} / \mathrm{l}$, e outro contendo ANA $0,1 \mathrm{mg} / \mathrm{l}$ e KIN 3 $\mathrm{mg} /$, houve a formação de embriões somáticos.

Como indicadores para uma segunda fase de experimentos, sugere-se novamente o uso de cotilédones como explante por ter sido seguramente o tecido que mais produziu calos, mas com o uso de uma outra fonte de auxina ao invés de TDZ ou mesmo este último, mas em dosagens menores que a testada neste experimento. Para a proliferação de calos, sugere-se repetir o experimento com uso de ANA e KIN por terem dando indícios da sua efetividade na formação de embriões somáticos.

\section{AGRADECIMENTOS:}

Agradecemos aos estagiários Adriana Tomazi pela profícua ajuda na instalação dos experimentos e Fabiano José Pickscius, Daniel Enriquez Hidalgo e Cassia Garrido durante as avaliações.

\section{BIBLIOGRAFIA CITADA}

Addison, G. O’N.; Tavares, R. M. 1951. Observações sobre as espécies do gênero Theobroma que ocorrem na Amazônia. Bol. Tec. do Inst. Agron. do Norte, 25: 1-41

Addison, G. O'N.; Tavares, R. M. 1952. Hybridation and grafting in species of Theobroma which occur in Amazonia. Evolution, 6(4): 380-386

Ayres, M.; Ayres, M.A. Jr.; Ayres, D.L.; Santos, A. S. dos 1998. BIOESTAT. Aplicações Estatísticas nas áreas das ciências Biológicas e Médicas. Sociedade Civil Mamirauá/ MCT - CNPQ, Belém, 193 p.

Blake, J.; Maxwell, P. 1984 Tissue culture propagation of cacao by the use of axillary buds. Proc. Int. Conf. Cocoa Coconuts. Kuala Lumpur, Malaysia.

Dufour, M., Dublin, P.1985. Quelques données nouvelles sur l'induction et le developpement d'embryons somatiques chez Theobroma cacao. Café Cacao Thé, 29:.235-244

Ferreira, M. das G. R; Cárdenas, F. E. N.; Carvalho, C. H. S. de; Carneiro, A. A. Damião Filho, C. F. 2001. Desenvolvimento de calos em explantes de cupuaçuzeiro (Theobroma grandiflorum) em função da concentração de auxinas e do meio líquido. Rev. Bras. de Fruticultura. 23(3): 473-476. 


\section{ACTA \\ AMAZONICA}

CALOGÊNESE DO HÍBRIDO Theobroma

grandiflorum X T. obovatum (STERCULIACEAE)
Figueira, A.; Janick, J. 1994. Optimizing carbon dioxide and light levels during in vitro culture of Theobroma cacao. Journal of the American Society of Horticulture Science, 119 (4): 865-871.

Figueira, A., Whipkey, A., Janick, J., 1991. Increased $\mathrm{CO}_{2}$ and light promote in vitro shoot growth and development of Theobroma cacao L. Journal of the American Society of Horticulture Science, 116(3): .585-589

Flynn, W.P., Glicenstein, L.J., Fritz, P.J., 1990. Theobroma cacao L.: An axillary bud in vitro propagation procedure. Plant Cell Org. Tiss. Cult., 20(2):.111-117.

Janick, J.; Whipkey, 1985. A. Axillary proliferation of shoots from cotyledonary nodal tissue of cacao. Revista Theobroma, 15(3):.125-131.

Li, Z.; Traore, A.; Maximova, S.; Guiltinan, M. J. 1998. Somatic embryogenesis and plant regeneration from floral explants of cacao (Theobroma cacao L.) using Thidiazurom. In Vitro Cell Dev Biol Plant. 34(4): 293-299.

Orchard, J.E., Collin, H.A., Hardwick, K. 1979. Culture of shoot apices of Theobroma cacao L. Physiol. Plant, 47: 207-210.

Passey, A.J.; Jones, O. P., 1983. Shoot proliferation and rooting in vitro of Theobroma cacao L. type Amelonado. Journal of Horticultural Science, 58(4): 589-592.
Sokal, R.R.; Rohlf, F.J. 1981. The Principles and Practice of Statistics in Biological Research (2nd ed.). San Francisco: State University of New York at Stony Brook, $776 \mathrm{p}$.

Tan, C.L.; Furtek, D.B. 2003. Development of an in vitro regeneration system for Theobroma cacao from mature tissues. Plant Science, 164: 407-412.

Velho, C. C.; Whipkey, A.; Janick, J. 1988. Cupuassu, a new beverage crop for Brazil. In: Advances in New Crops. Proceeding of the First National Symposium, New Crops: Research, Development, Economics. Janick, J. Simon, J.E. eds. Indianapolis, Indiana, oct. 23-26.

Venturieri, G. A. 1993. Cupuaçu: A Espécie, sua Cultura, Usos e Processamento. Clube do cupu, Belém PA, 118p.

Von Arnold, S., Eriksson, T. 1981 In vitro studies of adventitious shoot formation in Pinus contorta. Can. J. Bot., 59:870-874.

RECEBIDO EM: 06/06/03

ACEITO EM 21/09/04 
